\title{
International Cooperation in Agricultural Research and Development
}

\author{
John S. Niederhauser \\ College of Agriculture, University of Arizona, Tucson, AZ 85721
}

I am deeply honored to present the sixth annual William A. (Tex) Frazier Lecture. My participation allows me to join ASHS in recognizing the outstanding contributions that Frazier made to the world of horticultural science. Everywhere Frazier worked during his long and remarkable career, he left a definite contribution to horticultural crop production technology. This includes the two years he spent in Arizona, where he helped establish a strong vegetable industry and gave Arizona potato production a boost.

I am proud to join the previous Frazier lecturers in calling attention to the important contribution that horticulture can make in improving the quantity and quality of food available to feed the world. In 1989 David Hopper defined the role of horticulture in the economy and food supply of developing countries. In 1990 Frank Salisbury took us on a trip to the moon to discover how to produce food in space. And last year, E.T. York discussed the importance of agricultural sustainability as farmers try to increase food production while maintaining natural resources and the quality of the environment.

\section{THE CHALLENGE-THE CONQUEST OF HUNGER}

I mention these timely contributions because they are directly related to one of the most critical challenges confronting the world today: Will this planet be able to feed a rapidly increasing world population? A positive answer is possible only if world population stabilizes by 2100 at about 12 billion. An equally challenging question is: Can we feed this growing population while establishing a sustainable agriculture that will preserve the quality of our environment? The answer depends on our ability and discipline as citizens of one world to: 1) define and accept realistic goals and priorities; 2) use or develop the needed technology; and 3) establish strategies and international cooperation to implement the program. During this decade and as we enter a new millennium, this campaign to feed the world and preserve the quality of our environ-

Received for publication 17 Aug. 1992. This paper was presented as the William A. (Tex) Frazier Lecture at the 89th Annual Meeting of the American Society for Horticultural Science, Honolulu, Hawaii, 2 Aug. 1992.

Adjunct Professor.

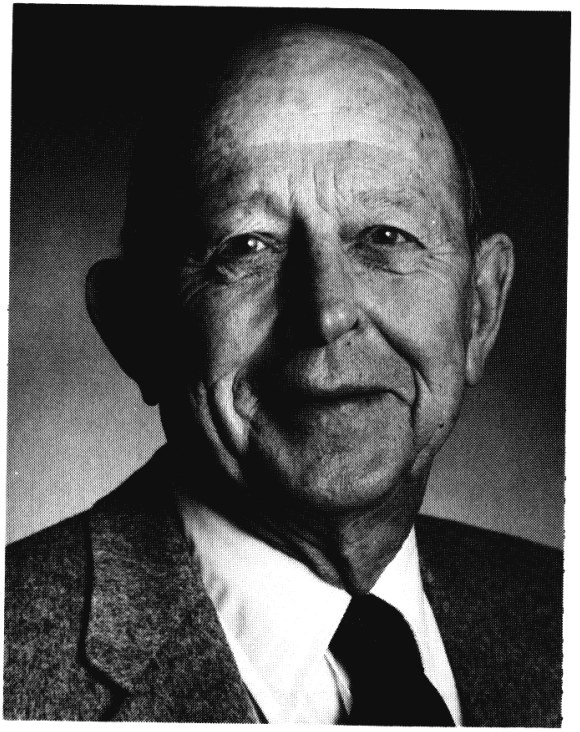

ment may be the most critical struggle for survival in the history of mankind.

\section{GOALS AND PRIORITIES}

The goal is simple, clear, and inspiring: end hunger and malnutrition in the world while preserving the quality of the environment and maintaining our natural resources.

The priorities, more complicated and controversial, are to: 1) produce enough food; 2) distribute it equitably; and 3) establish a sustainable agriculture.

\section{World food production}

Obviously, the production of enough food is basic to any solution of hunger. Much has happened to increase world food production during the past 40 years. The Green Revolution in wheat and rice production in Asia and Latin America has been followed by significant breakthroughs in other food crops, such as sorghum and potatoes.

By the 1980s nearly 4 billion tons of grain was produced worldwide, almost double the amount two decades ago. Today $2.3 \mathrm{~kg}$ of food is produced per person per day in the world. This increased production has allowed more grain to be stored, even in India and China, which have $40 \%$ of the world's population. This is in great contrast to 30 to 40 years ago, when great famines occurred every 2 to 3 years in these countries.

Despite these encouraging data, an alarm- ing paradox is emerging: food surpluses have grown worldwide, but so has hunger. The United Nations Food and Agriculture Organization (FAO) reports that, today, more than 700 million people are classified as hungry, The figure for those that are undernourished is much higher.

Apparently, adequate food production does not mean an automatic solution to hunger. Why?

Food production in developing countries. Although world food production has increased, many developing countries do not produce enough food to feed their populations. For example, due to rapid population growth, annual per capita food production is decreasing in large regions of Africa and Latin America. The resulting economic burden of importing food contributes to hunger.

Feeding a world population of 12 billion in 2100 , even if it has stabilized, will be a monumental task. Even more alarming is the fact that $90 \%$ of this total population will inhabit what are today the developing countries of the world. Thus, if we are to feed this expanding world population during the next century, it is imperative that more food be produced in the developing countries, and by higher productivity rather than simply by more area planted.

Private incentive and food production. Attempts to socialize agricultural production have been unsuccessful. The production of food crops is subject to too many unpredictable variables and individual, spontaneous decisions. Whenever the food producer (the farmer) is directly rewarded for higher yields--either in quantity, quality, or both-private incentive is stimulated and food production and productivity increase.

For example, during the past decade, the conversion of Chinese agricultural communes to groups of individual family holdings has sparked a spectacular rise in crop productivity. In Poland, more than $80 \%$ of the agricultural land has remained in small holdings in the private sector since 1945. Consequently, yields of important food and forage crops have been substantially higher in Poland than those in neighboring countries with state-controlled agricultural production systems.

Technology. Many believe that a lack of technology is the limiting factor in agricultural production, resulting in hunger. This is rarely the case. We do have the technology to increase food production dramatically in most 
parts of the world, but we lack the economic resources to use it efficiently in developing countries. We know how to put our farm lands on a sustainable base. However, a field-proven technology for increasing food productivity, while establishing and maintaining a sustainable agriculture, is still our greatest need and technological priority. This is true for all countries, developed and developing, but perhaps most critical in the latter.

Government policy. The use of available technologies is often made more difficult by contradictory government policies or the apathy of the decisionmakers. Inefficient coordination among official agencies and institutions can suppress or confuse the most worthy of production-oriented projects and prevent the wider use of new or established technologies. Again, this is true of both developed and developing countries. In affluent countries, for example, policymakers may decide they are not interested in disease-resistant cultivars or integrated pest management and may simply apply more chemicals to control pests. In poor countries with scarce resources, unstable governments and the lack of continuity in policies governing agricultural production and distribution can be potent contributors to hunger.

\section{Distribution and availability of food}

Poor distribution and reduced availability of food can result in hunger even when food is abundant. This is true of any country. Even in the United States, the largest food-exporting country in the world, about $12 \%$ of the people are hungry, and an even larger percentage is undernourished.

Any economic, political, or social factor that contributes to a lack of purchasing power in any sector of society is an important cause of hunger. These factors include poor marketing opportunities, postharvest losses, and inadequate transportation and storage facilities. Finally, and most importantly, an inescapable link exists between poverty and hunger.

\section{Sustainable agriculture}

We cannot continue to expand the area planted to food crops as a way to feed the increasing world population. The pressure on marginal lands is already at the danger point. The more pessimistic observers believe that we have already gone too far and that our planet is doomed.

If we merely continue to use more chemicals to fertilize our crops and control diseases and pests, the dangers to a sustainable agriculture are obvious. Any strategy to feed the world's population during the coming century must maintain environmental quality and natural resources. And, as York stated in 1991, "A truly sustainable agriculture must also be productive, and profitable."

\section{CURRENT ROLE OF THE POTATO AS A WORLD FOOD CROP}

In the remarkably short period of four centuries, the potato has emerged from the central Andean region of South America and become one of the four major food crops of the world, along with rice, wheat, and maize. Today the potato is a staple food in developed, industrialized countries and is becoming more important in developing countries.

Annual per capita consumption of potatoes in Europe, Russia, the United States, and Canada is several times higher than in the Third World countries of Asia and Africa. In Latin America, with the important exception of the Andean region where the cultivated potato originated, annual per capita consumption is also well below that of industrialized countries (Fig. 1).

Let us examine some of the recent trends in potato production and use, first in developed countries and then in developing countries.

\section{Developed countries}

Although the area planted to potatoes in developed countries has steadily declined during the past 40 years, productivity has significantly increased. As a result, total annual production has tended either to rise slowly or level off in these countries.

Canada and the United States are good examples of this trend. Annual potato production has been gradually rising during the past 20 years in both countries due to a steady increase in yield per hectare, while the area planted has remained fairly stable.

In several European countries, the potato is not only an important daily food for the people, but also a livestock fodder, particularly for swine; a source of starch; and a crop for processing. Any future decline in total potato consumption in Europe will probably be due, not to a reduction in human consumption, but to a shift from potatoes to cereal grains, both for starch production and livestock feed.
In Europe, the potential demand for processed potatoes has not been exploited; until recently, less than $20 \%$ was processed. In the United States, however, more than half the potato crop is processed and consumed as snack food.

\section{Developing countries}

During the past 45 years I have had the privilege of collaborating with colleagues in national potato programs in 78 countries, mostly in the developing world. In each country our main objectives were to 1) improve national potato production and productivity, thereby increasing per capita consumption of this valuable food crop; and 2) establish a strong national potato production program, with the resources and trained personnel to provide an operating base for continued contributions. These programs have been highly effective, and the potato has significantly increased in importance in many Third World countries. Potato production in these countries has been rising at a faster rate than that of any other food crop, due both to more hectares planted and higher yield per hectare.

Forty years ago the developing countries produced only $7 \%$ of the world's potato crop; today they produce more than $25 \%$ (Table 1). This dramatic increase in potato production was the result of dedicated efforts by national potato program personnel, with the enlightened support of national decisionmakers who appreciated the potential contribution of the potato to the diet and economy of their people. These countries used their own resources to apply advanced, production-oriented technologies for the development of better seed, more

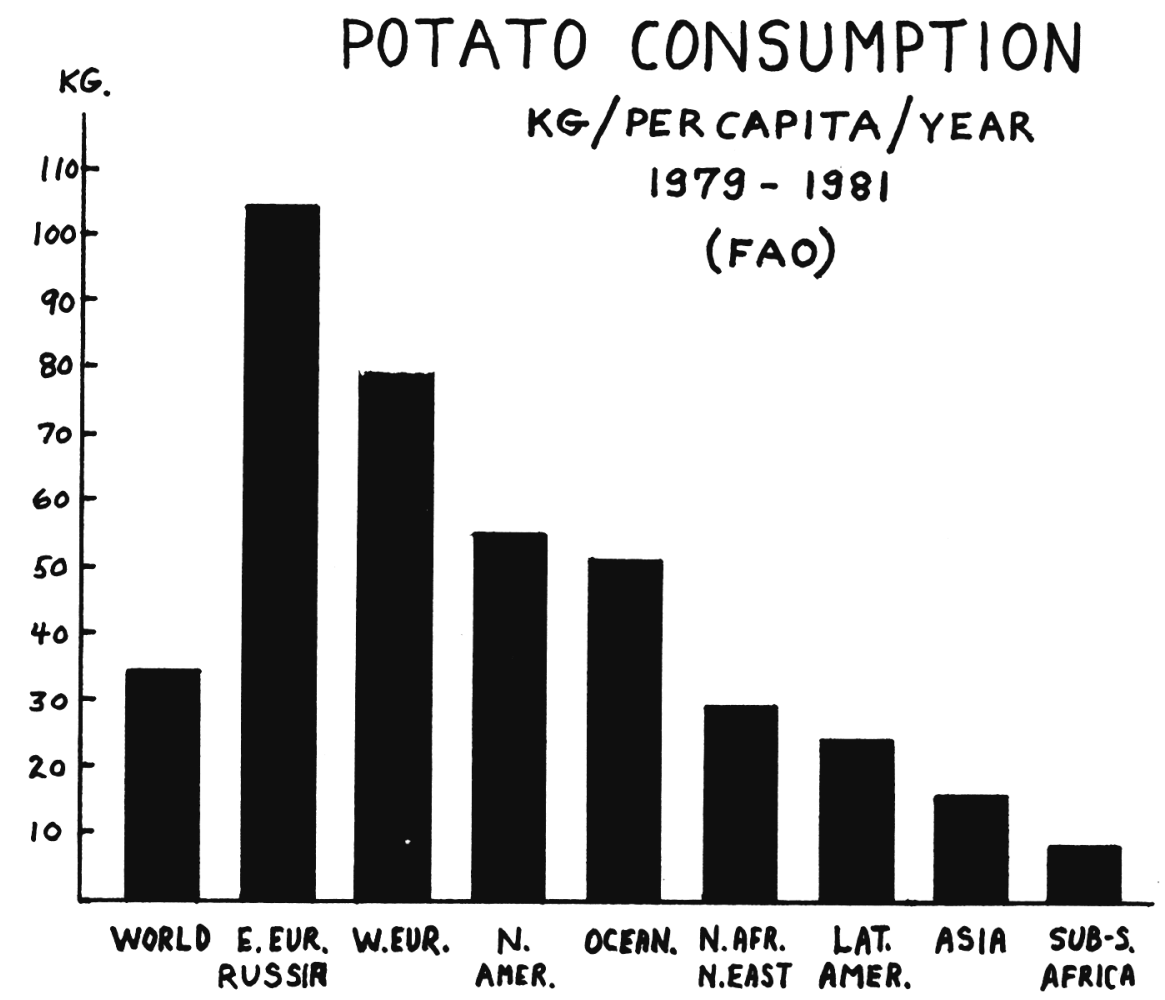

Fig. 1. World potato consumption (in kilograms per capita per year) from 1979 to 1981 (from the United Nations Food and Agricultural Organization). 
Table 1. World potato production (data from the United Nations Food and Agricultural Organization production yearbooks).

\begin{tabular}{lcrrr}
\hline \hline & $\begin{array}{c}\text { Area } \\
\text { Year }\end{array}$ & $\begin{array}{c}\text { Yield } \\
(\text { million }\end{array}$ & \multicolumn{2}{c}{ Production } \\
\cline { 4 - 5 }$\left(\mathrm{t} \cdot \mathrm{ha}^{-1}\right)$ & $($ total) & $(\%)$ \\
\hline $1948-52$ & & & & \\
World & 23 & 10.7 & 244 & \\
Developed & 20 & 11.4 & 224 & 92 \\
Developing & 3 & 6.4 & 20 & 8 \\
1969-71 & & & & \\
World & 20 & 13.8 & 277 & \\
Developed & 16 & 15.0 & 242 & 87 \\
Developing & 4 & 9.0 & 35 & 13 \\
1979-81 & & & & \\
World & 19 & 14.2 & 270 & \\
Developed & 13.5 & 15.5 & 209 & 78 \\
Developing & 5.5 & 11.0 & 61 & 22 \\
1986-88 & & & & \\
World & 18 & 15.5 & 281 & \\
Developed & 12 & 17.4 & 209 & 74 \\
Developing & 6 & 11.8 & 72 & 26 \\
\hline
\end{tabular}

productive cultivars, more efficient fertilizers and cultural practices, and effective disease and pest control (Fig. 2, Table 2).

A significant indication of the value and impact of a new staple food is the price consumers are willing to pay for that food. In urban Asian markets, the relative price of potatoes compared to that of rice had dropped substantially by 1980 (Table 3), due primarily to impressive increases in production and productivity. Thus, the potato was more available economically and was evolving from an expensive vegetable to a staple food.

The opening of markets for processed potato foods in Third World countries has been an important development in the past decade. Although the processing facilities may be installed by foreign investors, the potatoes are produced locally. This development could profoundly affect future potato production and consumption patterns in developing countries. However, the national potato programs and production trends in developed countries probably would be unaffected.

\section{POTENTIAL ROLE OF THE POTATO AS A WORLD FOOD CROP}

Let us examine some of the reasons for this dramatic increase in the importance of the potato in the nutrition of the Third World. Since the potato still is considered a horticultural crop in this region, could it serve as an example for other potential food crops? Could any of the strategies and programs responsible for this successful potato story be of value to government officials, scientists, and farmers from the Third World who are interested in making other horticultural crops more productive and available to improve the nutrition of their growing populations?

Perhaps, some of these new strategies would be of interest to you, Members of ASHS, as you attempt to increase the worldwide importance of the horticultural crops with which you are working. These other crops, as the potato, have great potential to contribute to the conquest of hunger, particularly in the sustainable agricultural systems of subsistence farmers in developing countries.
Criteria for evaluation of a food crop's potential to feed the world

It is important to evaluate a food crop's potential to help eradicate hunger before any substantial commitment to its development is made. The criteria, advantages and disadvantages, used to judge the potential of the potato as a food crop can be used to qualify other horticultural crops.

Why has the potato taken such a prominent role in feeding the world in a comparatively brief period? The potato has important advantages as a food crop, not only for producers and consumers in industrialized countries, but also for subsistence farmers working in the sustainable agriculture of developing countries.

The following advantages were compiled several years ago, when research on food production in space was initiated and the potential role of the potato in Controlled Environmental Life Support Systems (CELSS) was evaluated. I acknowledge the collaboration of Ted Tibbits and Ray Wheeler of the Univ. of Wisconsin and the National Aeronautics and Space Administration (NASA), respectively, and my colleagues at the BIOSPHERE project near Tucson, though they need take no responsibility for the accuracy or completeness of the following list.
High yield potential. The potato is one of the most efficient crops in converting natural resources, labor, and capital into a high-quality food with wide consumer acceptance. The potato is superior to almost every other crop in food production per hectare per day. It ranks first in energy production, significantly above cassava, cereals, and pulses. Among crops consumed fresh, the potato ranks first in protein production per day.

Excellent nutrient source. The potato is one of the world's most nutritious foods. The protein : carbohydrate ratio is higher in potatoes than in many cereals and other roots and tubers. Also, the value of the protein is higher than that of other major food crops (Fig. 3).

Highproportion of edible biomass. Potato tubers are $100 \%$ edible, and the foliage and roots can be used as fodder and silage for livestock.

Ease of preparation for consumption. The potato can be easily prepared for consumption by boiling, baking, frying, and processing.

Wide acceptance as a daily food. Today the potato is eaten daily by millions of people, but it had a fascinating history before being accepted as a food. During the 17th and 18th centuries, as the potato became an important food for the peasantry and working class,

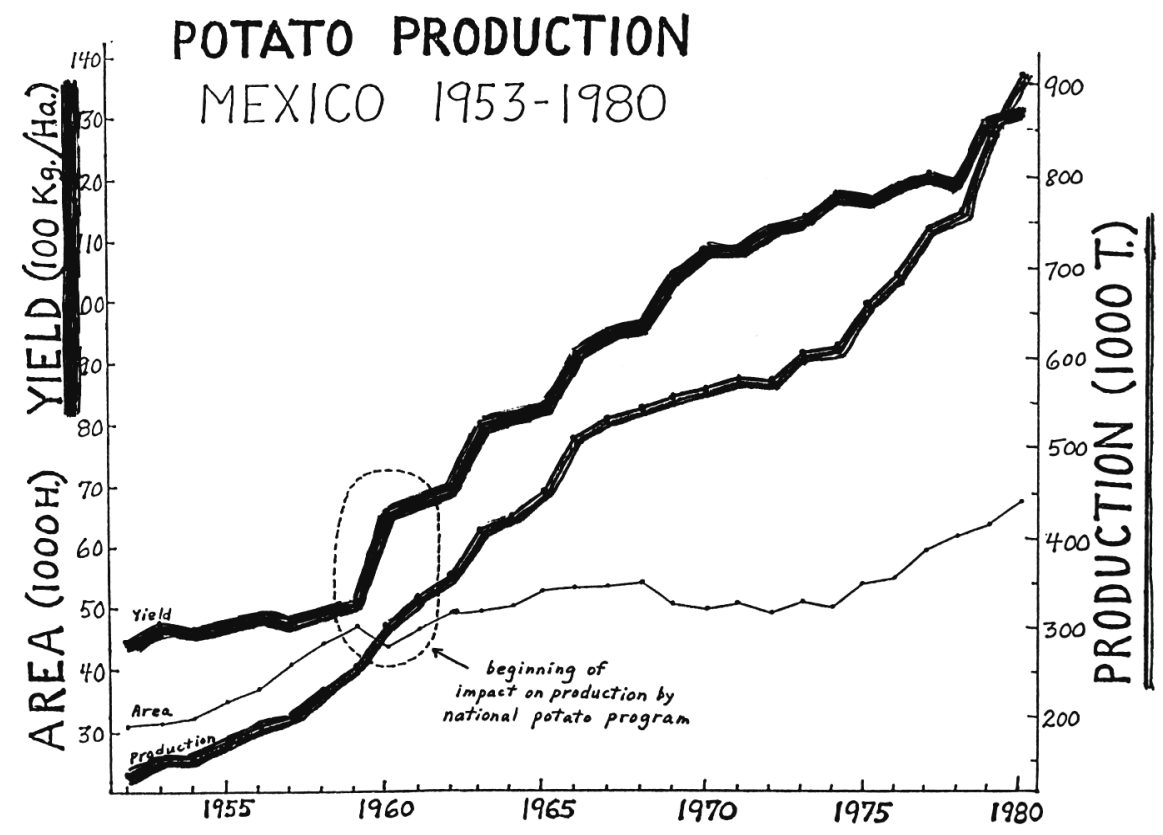

Fig. 2. Potato production in Mexico from 1953 to 1980. (Source: Direction General de Economia Agricola, Secretaria de Agricultura y Ganaderia; data obtained from annual reports, 1951-80).

Table 2. Increases in potato production from 1950 to 1980 (data from the United Nations Food and Agricultural Organization production yearbooks).

\begin{tabular}{|c|c|c|c|c|c|c|}
\hline \multirow[b]{2}{*}{ Country } & \multicolumn{3}{|c|}{$1948-52$} & \multicolumn{3}{|c|}{$1978-82$} \\
\hline & $\begin{array}{c}\text { Area } \\
(1000 \text { ha })\end{array}$ & $\mathrm{t} \cdot \mathrm{ha}^{-1}$ & $\begin{array}{c}\text { Annual } \\
\text { production } \\
(1000 \mathrm{t})\end{array}$ & $\begin{array}{c}\text { Area } \\
(1000 \text { ha })\end{array}$ & $\mathrm{t} \cdot \mathrm{ha} \mathrm{-}^{-1}$ & $\begin{array}{c}\text { Annual } \\
\text { production } \\
(1000 \mathrm{t})\end{array}$ \\
\hline Bangladesh $^{2}$ & 50 & 5 & 250 & 109 & 10.6 & 1,150 \\
\hline Colombia & 55 & 9.2 & 506 & 168 & 13 & 2,190 \\
\hline India & 277 & 6.8 & 1,547 & 806 & 15.2 & 12,250 \\
\hline Mexico & 30 & 4.5 & 134 & 69 & 15.8 & 1,094 \\
\hline Turkey & 79 & 7.7 & 605 & 190 & 16.8 & 3,200 \\
\hline
\end{tabular}

${ }^{2}$ Data for Bangladesh from 1948 to 1952 listed under East Pakistan. 
prejudices persisted and were transferred to those who cultivated and consumed it. Today the potato has gained acceptance as it is grown globally, and few people consider it an inferior staple food. Certainly, its acceptance in European countries, where potato consumption is highest, has confirmed its high rating as a daily food.

Adaptablefor intensivecultivation in small areas. Potatoes are ideally suited for the intensive, small-farm cropping system of the subsistence farmer. The expansion of potato production allows the agricultural sector to use a growing labor force productively.

Wide cultivar variety. There is no need to tell you of the great variation in yield, maturity, photoperiod sensitivity, vine growth, and tuber shape and quality among potato cultivars. Despite the diversity of potato cultivars, taxonomists (and students of genetic resources) report that, to date, we have used only a small fraction of the wealth of potato germplasmwild and cultivated-in Latin America.

Extensive production technology. Potato production technology is very well developed and has been proven in many environments. Its wider application is usually limited only by economic restraints.

Table 3. Relative price of potato vs. rice in developing countries (derived from International Lebour Review, Geneva).

\begin{tabular}{lcc}
\hline \hline Location & 1950 & 1980 \\
\hline Bangkok & 3.9 & 0.8 \\
Calcutta & 1.6 & 0.9 \\
Dhaka & 2.4 & 0.7 \\
Delhi & 1.2 & 0.9 \\
Manila & 1.6 & 1.3 \\
Mauritius & 0.9 & 0.4 \\
Seoul & 0.3 & 0.5 \\
\hline
\end{tabular}

'Price ratios are derived from J-year averages of retail prices.
Security of production under stressful environmental conditions. This is a subtle advantage not often given much consideration. For example, in the Andean region of South America, subsistence farmers often plant small plots of frost-resistant, wild potato species (e.g., Solanum juzepsukii and S. acaule) beside their fields of higher-yielding potato cultivars. In a severe frost during the growing season, the wild species will still yield a modest crop, while the other potatoes will be destroyed. Also, farmers in Poland have noted that an untimely frost or drought in the latter part of the season can destroy a grain crop, but the damaged potato will produce a partial crop.

Short crop season. The potato has a shorter growing cycle than most other food crops, especially in the tropics, and thus can be more easily incorporated into rotations and cropping systems. Agricultural officials and scientists in India report that the area planted to potato in the Punjab (a major potato production area) would shrink to less than half the area now planted if they did not have potato cultivars that could be harvested in 90 to 100 days, thus fitting into the annual rotation between winter wheat and summer rice.

Potato production also involves some distinct disadvantages and problems.

Bulkiness (in marketing, transport, storage, etc.). The bulkiness of this crop is evident to anyone who has harvested potatoes, weighed yields of research plots, or driven a truck load of potatoes. When we plant, harvest, market, or consume potatoes, we deal with about five times the equivalent amount of grain.

Perishability and postharvest losses. A major barrier to increased consumption of the potato in developing countries is its semiperishable nature and postharvest losses. In many developing countries, nearly one-third of the

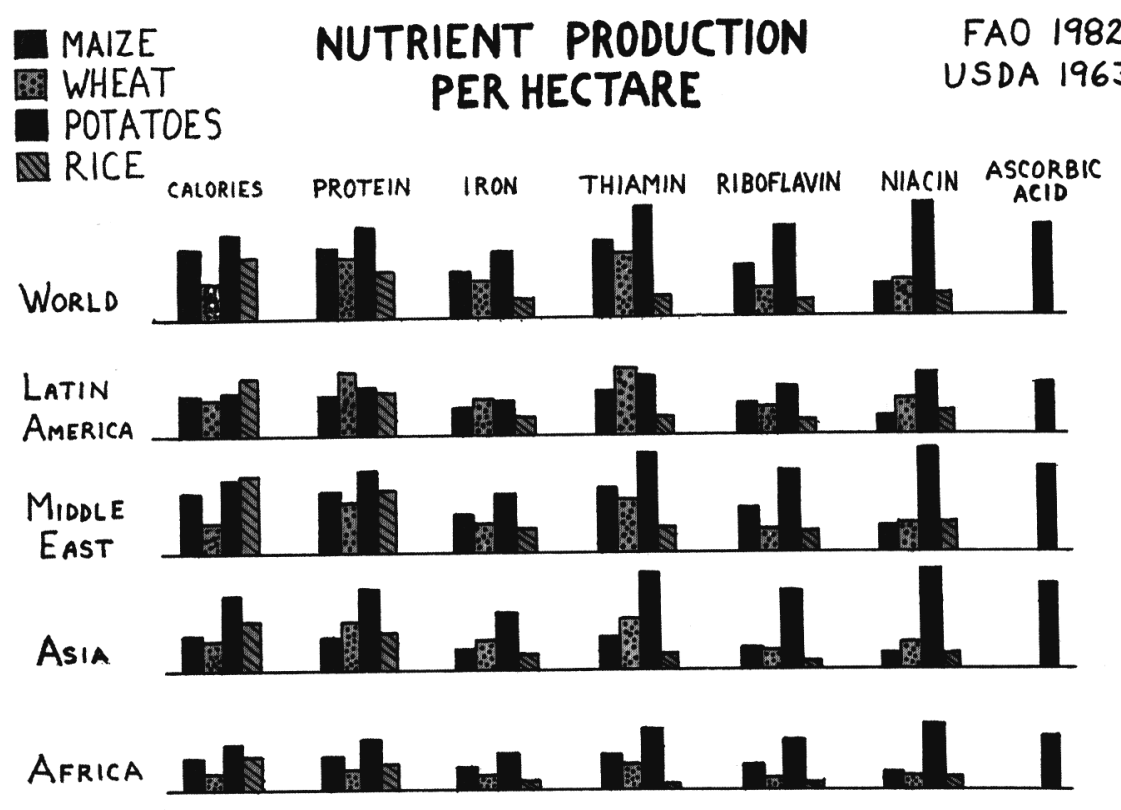

Fig. 3. The nutrient production per hectare of potatoes compared to maize, wheat, and rice for various countries and the world.

crop harvested never reaches the consumer, thus making the potato more expensive and less competitive with other food crops. Improved postharvest technology is critical to increasing potato consumption in the developing world. A modest investment in the conservation and efficient marketing of the harvested crop often would pay far greater dividends in the form of available food and better nutrition than would a similar investment in increasing crop yields.

Storage. Potato tubers turn green in light, and the solanin content can make them bitter, or even toxic. Low temperatures are required for long-term storage of potatoes.

Cool-climate crop. Most potato cultivars are grown in the cool climates of the temperate zones or at high altitudes in the tropics. During the past two decades, researchers have attempted to develop potato cultivars for the tropics and subtropics. The International Potato Center in Lima, Peru, is exploring the potential value of native Andean potato species and breeding selections in a search for cultivars that are better adapted to tropical conditions. The results are promising, but no spectacular breakthroughs have occurred. Other food plants, such as cassava and sweetpotato, are still more productive than the potato in warm tropical and subtropical regions.

Seed problems. The potato crop is conventionally grown from tuber seed, the source of many disease problems and the most costly potato production in developing countries, often accounting for more than $50 \%$ of the total production cost.

Disease control. The potato is host to many pathogens and pests-fungi, bacteria, viruses, nematodes, aphids, beetles, leafhoppers, etc., which have plagued potato growers around the world. The sharp rise in potato productivityfirst in developed countries and more recently in developing countries of the Third Worldis due in part to the successful control and management of these pathogens and pests. This campaign must be intensified if the current potato cultivars are to continue to rise in importance, particularly in developing countries.

This list of advantages and disadvantages is not complete and will change as our experience with growing the potato expands into new regions of the world. I do not doubt that more vegetable crops will have an important role in food production in these countries and in the nutrition of their people. How can we accomplish this? We first need to study each of these horticultural crops and judge them by the criteria listed above. How can we maximize the advantages of a potentially important vegetable crop? If disadvantages exist, how can we minimize them? Such information and decisions will help to determine the future role of horticultural crops in the subsistence agriculture of small-farm owners in the developing world.

Strategies for international cooperation in agricultural research and development

International cooperation is as old as hor- 
ticultural science itself. Beginning with visits and collaboration among individual scientists, it slowly expanded during the first half of this century. Before World War II, many fruitful interchanges of technology and plant material took place between scientists in Europe and North America. For example, Vavilov's and Bukasov's classic plant explorations in the Americas in the 1920s and 1930s generated worldwide interest not only in plant taxonomy, but also in genetic resources and the potential value of new food plants.

During the past 50 years, as means of communication have become more sophisticated and travel to distant regions has become more rapid, the tempo and volume of international cooperation have increased dramatically. We recognize that very few problems in agricultural research and development are unique to a single country and that few solutions are reached exclusively through national resources and personnel. Each of us is aware of the numerous opportunities to engage in collaborative research and development with colleagues from other countries.

We have seen how potato production has significantly increased in Third World countries during the past 40 years. However, it is also important to note that the rapid rate of increase in potato production in these countries has begun to slow down during the past decade. Why? And will this trend continue? The answers to these questions provide the guidelines for new strategies to help the potato contribute even more to the conquest of world hunger.

Let us now devote our attention to several new strategies in international cooperation, designed to resolve those factors limiting the continued rapid increase in potato production in developing countries.

PICTIPAPA-International coordination of research on potato late blight and its control. Late blight invaded Europe during the 1840 s, destroying the potato crop in Ireland in 1845 and causing the tragic Irish famine. Today potato late blight is still the most important potato disease worldwide and is the reason that the world's potato crop receives a higher total amount of chemicals annually than any other food crop.

In many developing countries, potato growers face a dilemma. Little, if any, water is available for expanding irrigated cropland. Thus, if more potatoes are to be grown, it will be under rainfall, and the currently available blight-susceptible cultivars will have to be sprayed with chemical fungicides to protect them from this disease. However, these fungicides are often unavailable or too expensive for Third World subsistence farmers. Moreover, environmental concerns would deter expanded use of agricultural chemicals. Thus, if the potato is to resume its accelerated role in feeding Third World populations, cultivars resistant to late blight are needed.

Fortunately, during the past 45 years, an international cooperative program has developed potato cultivars with a durable resistance to late blight. This program, based in Mexico, where the causal fungus Phytophthorainfestans originated, has released more than 25 potato cultivars with high levels of resistance. Some of these selections have been grown successfully without chemical protection for 20 years by subsistence farmers in the mountainous regions of central Mexico.

Resistant Mexican potato selections have also been grown for several years by subsistence farmers in the Philippines, Nepal, Costa Rica, and Guatemala. Although these selections have contributed substantially to the food supply in these countries, they still have an enormous unexploited potential for food production in other countries of the developing world.

To realize this potential, the Mexican government launched a new international cooperative project in Aug. 1990 with the initial collaboration of scientists from Poland, the Netherlands, Canada, the United States, Mexico, and the International Potato Center. This project, called the International Cooperative Potato Late Blight Program (PICTIPAPA), fosters the international testing, distribution, and multiplication of blight-resistant potato cultivars throughout the world and makes this plant material available to owners of small subsistence farms in any country.

The program represents a new strategy in international cooperation, in which a Third World country, Mexico, provides its national program as the operating base for a worldwide collaboration. Mexico was chosen because of the unique comparative advantages it offers for the study of potato late blight.

The Mexican blight-resistant potato cultivars represent the most promising plant material for expanding world food production since the short-strawed, rust-resistant wheat and "miracle rice" cultivars launched during the Green Revolution. These Mexican cultivars could launch a new truly Green Revolution, using fewer chemicals, to increase food production.

Scarce economic resources. Today, many developing countries have strong national agricultural institutions and trained personnel The factors that limit increased food production and use have been defined in most cases, and the needed technology has been developed. However, scarce national economic resources often prevent the implementation of the strategies and programs needed for progress and solutions. Production-oriented, cost-effective, international cooperative programs are needed to maximize the use of proven technologies by all participants and to solve problems of mutual interest. This international cooperation must also include all factors involved in improving world food productionplanting, cultivating, harvesting, and marketing.

1) Regional cooperation. During the $1970 \mathrm{~s}$ the national resources needed for agricultural research and development were lacking or limited in Central America. It was not possible for each country to finance acomplete national potato production program, with all the necessary technical personnel and components. To alleviate the problems caused by this lack of funds and resources, the Regional Coopera- tive Potato Program (PRECODEPA) was established in 1978 at a meeting attended by representatives from Guatemala, Mexico, Honduras, Costa Rica, Panama, the Dominican Republic, and the International Potato Center. Today representatives from 10 countries and the International Potato Center participate in the program.

At the organizational meeting in Guatemala, each representative listed the factors limiting the increase of potato production and productivity in their country. Many of these factors-good seed, late-blight resistance, lowcost rustic storage-were common to several or all countries, and a regional project was organized to solve each. Leadership for each project was assigned to one of the collaborating national programs, which, with international financial support, developed the personnel, research, and materials needed to solve each production problem. The research technology and training opportunities derived from these projects were shared with each interested country.

Among the benefits to the participating countries during the past 10 years have been increased potato production and productivity, greater continuity in national program activities and personnel, and more efficient use of scarce resources. Only by sharing results and solutions for food production problems can most developing countries take advantage of the new technologies available for increasing food crop productivity.

PRECODEPA has been recognized as a very cost-efficient strategy for improving agricultural production and productivity in countries with limited resources and has served as a model for similar cooperative programs in other regions of the world. Many believe that it could be the most important new development in the transfer of technology since the creation in the 1960s of the International Agricultural Research Centers.

2) Private sector. Food research and technology is of basic importance to every nation, and the opportunities for economically valid collaboration with the private sector are almost unlimited as the global food market expands. However, I caution that new international ventures should be developed with the cooperation and support of local national institutions, including the agricultural sector and farmers, not in conflict or competition with them. Projects of mutual interest and benefit lead to better economic growth in all participating countries, making them more valuable partners in the future.

The establishment in the 1960s of Sabritas, a Mexican enterprise of Frito Lay, the U.S. snack food manufacturer, exemplifies a successful international agribusinessventure. The early operating base of Sabritas consisted of 37 bicycles serving a few hundred stores, most in Mexico City, with a total annual sales of about $\$ 600,000$. During the past 25 years, Sabritas has grown into a food industry and distribution giant, with more than 5000 trucks serving 350,000 outlets and annual sales of more than $\$ 1$ billion.

The guiding force behind the remarkable 
success of this food enterprise was the dedicated and intelligent leadership of John Warner, the founder of Sabritas and its president until his recent retirement. Warner had not only the executive talent and technical knowledge to create and lead this successful commercial operation, but also the wisdom and personality to merge Sabritas into the national scene, gaining the respect and admiration of the agricultural sector.

As the company grew and prospered, Warner shared his success with local farmers and national institutions involved in food production. Production contracts with growers, collaboration with the national certified seed program, and support of national research programs in areas of mutual interest created a firm national base on which the company could grow and a stronger national food production program in accordance with national priorities.

Sabritas is an excellent example of a highly profitable international agribusiness venture that builds strength and continuity in the national program. This case shows the great international opportunities awaiting the food industry, when the encouragement and support of national institutions and programs are given priority alongside the commercial goals of the business.

It is my hope and recommendation that members of the private sector, as they pursue their commercial goals internationally, will not neglect the mutual benefits to be gained from sharing food production and processing technology with the Third World. With its combined resources of excellent personnel, advanced technology, and a vision of expanding international cooperation, the private sector could be at the beginning of a most exciting and fruitful period.

3) National foundations. Recently, international donors have been searching for innovative ways to strengthen national agricultural productionsystems. One of the more promising new strategies is the National Foundation for Agricultural Research and Development, sponsored by the private sector and financed by private and public funds. This nonprofit foundation is independent in its operations and management but closely related to government agricultural priorities and strategies.

The oldest such foundation is the Honduran Agricultural Research Foundation (FHIA), which conducts research on traditional and nontraditional food crops in Honduras. FHIA emphasizes research in certain priority areas, including vegetable crops, mango, pineapple, pepper, and palm hearts.

In 1987 the Ecuadorian Agricultural Development Foundation (Fundagro) was established. It serves as a catalyst to link the public and private sectors in supporting national research, extension, and education opportunities.

Positive results to date indicate: 1) better coordination between national institutions in shared priority programs, 2) more cost-efficient use of scarce national resources, and 3) a stronger link with international sources of technology.

New strategies for international cooperation. The International Science Corps and regional production and training centers are two initiatives that could add new dimensions to international cooperation in agricultural research and development.

The establishment of an International Science Corps, which is proposed here for your comments, would provide opportunities primarily for students and young professionals to obtain international experience. The related fields of food production, processing, and marketing would be included. This program would be organized, administered, and financed as a collaborative venture involving the private sector, appropriate government agencies (such as the U.S. Agency for International Development and the Peace Corps), and scientific and educational institutions.

The exciting opportunities for international involvement in the food production sciences makes a coordinated national endeavor that would provide professional experience in other regions of the world an urgent necessity.

We shall need new generations of young professionals who have the vision and experience to undertake the new worldwide cooperative ventures in food production, processing, and marketing.

In 1985 the Univ. of Arizona established the Maricopa Agricultural Center (MAC) on 851 ha of flat, irrigated land between Tucson and Phoenix. Governed through the Univ. of Arizona Foundation, MAC devotes 162 ha to the university's agricultural research programs, with the remaining 689 ha operated as a commercial farm for profit. The most modem production technologies are used to produce high yields of such local crops as cotton, alfalfa, wheat, and grapes. Profits are used to defray all costs of operation and encourage the development of new crops and technologies.
Unique production training opportunities are available for graduate students, both national and international.

Looking to the future, other regional production and training centers are being planned for Africa (Morocco), the Middle East (Kuwait), Asia (Pakistan), and Latin America (Mexico). Preference is being given to regions with arid climates, similar to that in Arizona, and regions where the pressure on efficient, sustainable agricultural production is so critical.

The regional production and training centers would 1) develop the newest production technologies at the farm level and test their economicviability; 2) provide an international base for field-oriented production training for scientists from countries with similar climate stresses; 3) coordinate and develop research on new production technologies in arid agricultural zones; and 4) be financially self-supporting.

\section{CONCLUSION}

ASHS has a fine history of international cooperation, both as a Society and as individual scientists. Your International Affairs Division is designed to promote productive, cost-efficient international collaboration on projects of mutual interest.

I believe that some of the strategies and experiences discussed here might encourage the Society to continue its role in these international agricultural research and development activities.

The horticultural crops of the world are invaluable agricultural resources that have realized only a fraction of their potential in providing food and high-quality nutrition to the people of the world, particularly in developing countries. Let us make these valuable food plants available to everyone, through an intensive, small-scale, subsistence agriculture that is also sustainable.

We are living in one of the most exciting and critical periods in the history of mankind. As we approach the biological limits for what this planet can support, we must realize that we are living in one world. And as citizens of one world, we must collaborate with dedication toward a single goal-a world without hunger that conserves the quality of our environment and our natural resources.

I ask again: Are we equal to the challenge? 